\title{
Research on the New Pattern and Methodology of Enterprise Operation and Management in the Big Data Information Era
}

\author{
Dahai Wang ${ }^{1}$ \\ ${ }^{1}$ Northeast Normal University Humanities College, \\ Changchun,Jilin, 130117 China
}

\begin{abstract}
In this paper, we conduct research on the new pattern and methodology of enterprise operation and management in the big data information era. Under the environment of big data management decision puts forward new requirements on knowledge discovery. Big data mass, value diversity, dynamic and sparse, make the results of traditional optimization and algorithm accuracy is not fit for the big data knowledge discovery method, advantages and disadvantages of metrics also does not apply to the traditional data mining method based on sample learning, knowledge discovery method based on the data has become a great new way of data knowledge discovery. In the future, we plan to conduct more in-depth research to modify the current idea.
\end{abstract}

Keywords: Enterprise Operation; Big Data Information Era; Effective Management.

\section{Introduction}

Enterprise management, is refers to the enterprise according to their own internal and external environmental factors of actual situation of the changes and its own resources, how to adapt to change and how to maintain the stable, healthy and sustainable development of the enterprise for the logistics planning and decision-making activities. Say simply, enterprise management is to the survival and development of the enterprise strategy planning and decision-making activities. Enterprise management is refers to the enterprises to realize strategy target and business objectives and plan, organize, command, coordination and control and so on a series of work activities. From the perspective of the definition of enterprise management, enterprise management is the study of the enterprise's survival and development and it needs from the overall situation of the enterprise, for the long-term development of the enterprise overall planning. For enterprises, enterprise management is the macro, it has the overall importance, insufficiency and challenging. From the definition of enterprise management, enterprise management is make full use of the existing of people, goods, content resources, using scientific and reasonable management mode and management method, maximum limit to mobilize enterprise internal staff enthusiasm, initiative and creativity to achieve the management of the enterprise strategic target and business objectives. For enterprises, enterprise management is the microcosmic and it has the scientific, artistic and practical.

Now Chinese companies don't have to debate whether to information, but today's Chinese enterprises how to survive in an increasingly digital world, from this perspective, the information itself must be part of the development strategy of Chinese enterprises, to escape the information of enterprises in the future of the Chinese society will be more and more difficult to survive, therefore this thesis should be how Chinese enterprises by the application of information technology, especially information technology to realize strategic value. The content of the enterprise management is shown as the follows. (1) Gradually cultivate and establish enterprise's core competitive advantage. Enterprises want to long-term survival and development, must build up its own core competitive advantage. (2) Always pay attention 
to and study of domestic and international politics, economy, culture, science and technology and the development of the market change, with keen smell angles and perspectives, accurately find the opportunities and threats of enterprise development and actively with preparation and plan in a timely manner. (3) To research and analyze the running state of enterprise management, find out problems, study countermeasures, to further improve and improve the quality of operations. (4) Create a good business environment to the enterprise. Business operators should try to get along with all departments and all aspects, get the support of all parties, as far as possible to reduce the constraints of enterprise development, build a good business environment to the enterprise. (5) Research on enterprise development strategy and business strategy in the future. Managers deal with the future development of opportunities and threats of careful research, to the enterprise in the industry, the development of the industry and market changes to be more accurate predictions, for the future management of the enterprise development strategy and business strategy.

The execution of the enterprise development strategy is the need to rely on enterprise multiple elements to cooperate with each other, to the people, processes, technology to do as a whole the organization and arrangement. Enterprise architecture is a comprehensive description of enterprise angles and it reflects the enterprise's people, process, technology, organization and arrangement, like corporate gene which decided the enterprise's development direction and results.

To combine the enterprise with the information and big data, in this paper, we conduct research on the new pattern and methodology of enterprise operation and management in the big data information era. Enterprise management is a science and enterprise management is also a science. For the corporate world, find out the difference between the enterprise management and enterprise management and contact, will not only help companies define operators and managers' professional role, is advantageous to the operators and managers responsibility division of labor, make the operators and managers can work according to their requirements, avoid dislocation, and can help companies to deepen the understanding of the importance of enterprise management, in order to pay more attention to and to carry out the work of enterprise management [1-4]. In the follow sub-sections, we will discuss the theory in detail.

\section{Our Proposed Methodology}

The Influence of Big Data for Enterprise Management. With the rapid growth of data, the time has come for a big data. Big data under the decision depends on a large number of market data, how to effectively collect and distribute data, reliable, intelligent analysis and perform data become the challenge for the future. Big data based on cloud computing environment affect the enterprise information collection methods, decision-making plan formulation, scheme selection and evaluation of decision-making and implementation process, which influence on the enterprise management decision. Research shows that the more data driven enterprise, financial and operational performance, the better. Big data is a very rich set of data, the data is an important production factor and the knowledge economy era is the fundamental resource in the economic operation. It can be expected that the future decision, evaluation of enterprise value is the maximum core data, the accumulation of data, data analysis, data driven business will be the main factor of enterprise value.

Under the big data decision-making technology content and knowledge content increased, the effective use of big data become the key to business decisions, so to manage a large amount of data is a challenge, if you can't find the data, enterprises cannot collect data, the data will be lost. Big data era requires companies not only have the ability to collect analysis data, 
need more enterprise has the ability of processing and use of these data. The challenges for the enterprise under the huge and big data environment could be summarized as the follows. (1) Real-time analysis for the data. With the rapid development of economy, the enterprise faces in a rapidly changing market, enterprises have already can't deal with the after process of conventional mechanism, the enterprise needs to real-time insight into business operation state, in order to quickly respond to changing market conditions. (2) Data link across business platform. In the enterprise data is separated by the division of business module. A single business module of associated data value is far less than all the business module data were analyzed using, the enterprise will be how to realize the data connection and integration across business platform will face a huge challenge. (3) Unity and integration of unstructured and structured data. With the rapid development of Internet and communication technology, the enterprise data type is not a single text primarily structured data already, also filled with widely exist in social networks. But the enterprise existing data processing method is only applicable to structured data, to a great deal of structured data and unstructured data are unified, integration, will not be able to explore the value of the data. (4) The general data-driven strategic decisions. Social networks, mobile Internet, enterprise information rapid development in recent years, constantly produce huge amounts of data will be more and more influence all aspects of the enterprise from tactics to strategy formulation.

Enterprise boundary problem research is always the classical economics and new institutional economics, strategic management an important issue. Enterprise boundaries including the longitudinal and lateral border, in the research of lateral boundary problem is the number of products or services, the problem is in the study of the vertical boundary in the production of a product or service, enterprises engaged in the scope. For enterprise vertical boundary, the scholars from the perspective of transaction cost theory, enterprise competence theory, form the two main points of view. This is because there are specialized products on the market or supplier, compared with the enterprise, it has the advantage of economies of scale and learning curve, and its production cost is lower than the cost of production enterprises. However, due to internal production costs and suppliers the cost of production will be affected by the large data also. So the ignore big data influence on the cost of production, consider only big data for internal coordination costs and the influence.

The Enterprise Operation and Management. In terms of enterprise operation and management, is refers to under certain social and economic conditions, in the process of enterprise development from the working procedures to the behavior way, management style, thinking habits and values would be a particular type of some internal consistent state. Enterprise operation and management mode must be adapted to the external environment, when a great change of the environmental conditions, inevitable requirement of enterprise operation and management mode and adjust accordingly. The advent of the era of network economy, greatly shorten the time, cost, information exchange has also changed the method of communication which makes the communication become more extensive, convenient and active and the emergence of the Internet economy.

Traditional organizational structure with linear system, unity form the structure of the organization, from top to bottom layers of transfer and arranged layout task model, will be rushed across the network economic spring tide, the middle of the huge loss management, the basis of management level, enterprises tend to be more flat organizational structure system. This is because: first, due to the application of computer technology and network technology which will make the enterprise internal and external 
information transfer more convenient, direct, a large number of original fluctuation at all levels within the organization communication information in the middle of the organization can be deleted, and thus reduce the management level, enhance the reflect the ability of the organization; Second, in the era of network economy, the enterprise all departments and personnel should fully understand and master all kinds of information, more directly in the face of the market, it has also encouraged companies to minimize the middle level, ensure the flat organization structure, because the flat structure is one of the advantages of reducing the delay of the decision making and operation, speed up the dynamic changes of the market and competition.

In the increasingly fierce competition in the market economy, enterprises must keep or enhance their competitive ability, strive for the active position in competition, using the information technology strategy will become a part of the enterprise infrastructure, and as sharp or secret weapon in the enterprise competition. Peace and development has become an irreversible historical trend in the world, economic development has become the country's general requirements, the entrepreneur is, of course, should become the protagonist of this era, in our country has already entered a taking economic construction as the center of the new historical period, in order to adapt to the development of socialist market economy and the establishment of modern enterprise system request, the current need is the modern management personnel, especially need to create a powerful entrepreneurs team as soon as possible, or form the influential entrepreneur class, this is not only the urgent need of economic development in our country and also is the call of The Times and requirements.

The Novel Pattern and Methodology. Enterprise management is the enterprise production and business operation activities of the organization, planning, command, supervision and regulation and a series of the floorboard of the function. Enterprise's management and directs the whole process of enterprise management, both have will be inseparable connection, but the enterprise and the management is not a concept, only the correct understanding of the relationship between them, the enterprise can achieve scientific management and effective management, to achieve maximum economic efficiency of enterprises. Operation strategy must conform to the enterprise management concept and objective standard, on the basis of making a business strategy under the premise, in consideration of internal and external environment opportunities and opportunities, on the basis of certain relations in line with the enterprise environment, thus the scope of business, growth direction of directional enterprise and market positioning, reasonably adjust the structure of the enterprise internal and external distribution and resource allocation. Enterprise management strategy which need to enterprise's present situation objectively evaluate the advantages and disadvantages, and then select and determine the enterprise's overall, long-term goal, to develop and achieve the goal of action.

Under the dynamic environment, decentralized decision making structure may be more important, and IT is usually as a means to improve enterprise in the dynamic changes in the environment data processing ability. In addition, enterprise organization structure in the intellectual distribution rights, knowledge transfer cost and transfer cost, if senior leaders concentrated distribution of knowledge, the corresponding centralized decision-making structure if the scattered distribution of knowledge, the corresponding structure of decentralized decision making. Big data under the policy-making environment more complex, decision-making timeliness is strong and more extensive distribution of decision knowledge, decentralized decision-making under big data as the main form. From the point of decision-making power distribution, low 
efficiency of enterprise decision one of the reasons is that there is no decision permissions assigned to the appropriate roles.

\section{Conclusion}

In this paper, we conduct research on the new pattern and methodology of enterprise operation and management in the big data information era. In the era of big data, on the depth of data mining can get more knowledge, enterprise can greatly benefit from it. Under the big data companies can learn more about business thoroughly, use knowledge to improve decision making and performance. Big data era, ordinary employees also have the right decision, the trend of flat organization structure will be more clear, the decision-making power allocation should conform to this change. Collect and analyze massive amounts of data, and rapid access to influence the ability of future information, is the charm of the big data technology. In the process of management decision, the data of used cannot be replaced, but need the data combination of objective and human's subjective decisions. Decision making participants in the era of big data is still the most important decision factors. Big data has changed for a long time, the theory and the thought way of management decisions based on the experience and intuition to precise data analysis, decision-making under the big data participants role has changed. In the future, we will conduct more related research to polish our current idea.

\section{References}

[1] Chuangxue X U, Wen X, Zhou J, et al. Cloud computing industrial video cascade based online monitoring and management system for enterprise operation: development and application $[\mathrm{J}]$. Thermal Power Generation, 2014.

[2] Wei X F, Song X L. Research of IT Operation and Maintenance Cockpit System for Enterprise Business Transformation[J]. Electric Power Information \& Communication Technology, 2014.

[3] Xiao Q S, Wei W U, Zhang P F, et al. Operation Risk Management System Model and Control Mechanism in Power Grid Enterprise[J]. East China Electric Power, 2014.

[4] Xing M. Research on the Enterprise Finance and Capital Operation under the ERP Management Balance[J]. Applied Mechanics \& Materials, 2014, 687-691. 